\title{
ANALISIS SEMIOTIKA RIFFATERRE DALAM LAGU SAKURA KARYA NAOTARO MORIYAMA
}

\author{
A.K.U.D.A. Mandala', P.T.K. Dewi ${ }^{2}$, N.K. Dwipayanti ${ }^{3}$ \\ 123Jurusan Bahasa Asing, Universitas Pendidikan Ganesha, Singaraja \\ e-mail : ayu.kris@undiksha.ac.id, tiara.karunia@undiksha.ac.id, dwipayanti@undiksha.ac.id
}

\begin{abstract}
Abstrak
Lagu Sakura adalah lagu yang ditulis oleh Naotaro Moriyama, yang dirilis pada tahun 2003. Lagu ini menceritakan perpisahan antara sahabat karena impian masing-masing. Tujuan penelitian ini adalah untuk mengetahui makna dalam lagu Sakura. "Sakura" pada lagu ini, sebagai pertanda akan perpisahan.Inilah yang melatarbelakangi ketertarikan penulis untuk mengkaji lebih dalam makna dan pesan yang terkandung di dalam lagu ini. Adapun metode yang digunakan dalam penelitian ini adalah metode deskriptif, studi pustaka, kualitatif dan hermeneutika Untuk mengkajinya, digunakan teori puisi Riffaterre. Melalui proses pembacaan heuristik dan hermeneutik, diperoleh hasil bahwa makna yang terkandung dalam lagu ini adalah perpisahan, impian dan keinginan untuk berjumpa lagi.
\end{abstract}

Kata kunci : semiotika Riffaterre, perpisahan, harapan

\section{Abstract}

Sakura is a song written by Naotaro Moriyama, released in 2003. This song tells the farewell between friends because of each other's dreams. The purpose of this research is to find out the meaning in sakura song. Sakura on this song, as a sign of separation. This is the background of the author's interest to examine more deeply the meaning and message contained in this song. The methods used in this study are descriptive methods, library studies, qualitative and hermeneutics To study them, riffaterre poetry theory is used. Through the process of reading heuristics and hermeneutics, the result is obtained that the meaning contained in this song is separation, dreams and desire to meet again.

Keywords: semiotics Riffaterre, farewell, hope

\section{Pendahuluan}

Lagu adalah syair yang dilafalkan sesuai nada, ritme, birama, dan melodi tertentu sehingga membentuk harmoni. Tentu saja, setiap syair/larik lagu memiliki makna tersirat yang ingin disampaikan oleh produser lagu kepada pendengar. Menurut (Wicaksono:1), karya sastra adalah bentuk kreativitas dalam bahasa yang indah, yang berisi sederetan pengalaman batin dan imajinasi yang berasal dari penghayatan realitas sosial pengarang. Budhidharma (2001:9), menjelaskan "meskipun sebuah lagu adalah curahan hati pribadi seseorang, tetapi seharusnya memiliki isi yang universal sehingga orang lain dapat merasakan apa yang tertuang dalam lagu".

Lagu Sakura merupakan lagu hasil karya Naotaro Moriyama yang dirilis pada tahun 2003. Dilihat dari judul lagu tersebut yaitu "Sakura", merupakan bunga yang tumbuh pada musim semi. Pada saat bunga sakura bermekaran, biasanya menjadi penanda bahwa waktu kelulusan telah tiba. Jika mendengar secara sekilas lagu ini, akan terdengar beberapa pengulangan yang menyebutkan kata "sakura". Dalam hal ini dapat dipahami maksud atau isi pesan dari lagu tersebut secara sepintas, yaitu tentang sebuah perpisahan. Perpisahan yang harus terjadi saat kelulusan, yang ditandai dengan mekarnya bunga sakura.

Lagu merupakan sebuah wadah bagi pengarangnya untuk berekspresi dalam menyampaikan pesan kepada pendengarnya. Tidak jarang di dalam lirik lagu terdapat katakata yang memiliki makna eksplisit, yang mana para pendengar lagu harus mencari tahu atau mengkaji terlebih dahulu lirik lagu tersebut.

Lagu termasuk ke dalam karya sastra (puisi) menurut Moeliono (2003:678). Berdasarkan pengertian tersebut, teori Riffaterre kemudian digunakan oleh penulis sebagai teori yang tepat untuk digunakan pada penelitian ini. Michael Riffaterre merupakan kritikus 
sastra. la berasal dari Perancis dan telah banyak berkontribusi pada bidang sastra. Riffaterre bahkan menghasilkan sebuah karya berupa buku dengan judul Semiotics of Poetry. Pada buku tersebut, Riffaterre menjelaskan bahwa dalam menganalisis suatu karya sastra (puisi) adapun 4 hal atau tahapan yang harus dilakukan, di antaranya adalah (1) ketidaklangsungan ekspresi, (2) pembacaan heuristik dan hermeneutik, (3) matriks, model, dan varian-varian, serta (4) hipogram. 'Teori Riffaterre dapat digunakan untuk menganalisis makna lagu yang terdapat pada lirik lagu Sakura. Melalui pembacaan heuristik dan hermeneutik kita bisa menemukan makna sebenarnya yang terkandung dalam lirik lagu Sakura. Pembacaan heuristik adalah pembacaan tahap pertama dengan membaca keseluruhan teks puisi yang menghasilkan makna teks berdasarkan unsur-unsur linguistik pembentuknya, berdasarkan tata bahasa normatifnya, atau didasarkan pada konvensi bahasanya yang meliputi unsur linguistik fonologi, morfologi, sintaksis, dan semantik. Pembacaan heuristik disebut juga dengan parafrase, yaitu proses memparagrafkan atau menarasikan suatu puisi. Dan Pembacaan hermeneutik atau bisa juga disebut dengan pembacaan retroaktif (berulangulang). Pembacaan ini proses decoding,yakni pembaca menafsirkan 'kejanggalan/ketidakgramatikalan' ataupun makna 'dibalik' teks yang ada dalam puisi. Dalam proses ini penulis berusaha menemukan makna 'yang dimaksudkan' yang biasanya terjadi sebagai dampak penggunaan ekspresi bahasa tidak langsung yang ditemukan pada proses pembacaan heuristik. Hasil pembacaan hermeneutik adalah pembaca dapat menemukan kesatuan makna puisi yang dibacanya.

Penggunaan teori Riffaterre sendiri sudah banyak dikaji, seperti pada penelitian Noviana dkk, (2020:143-160) yang menjelaskan tentang "Pemaknaan Lirik Lagu Shabondama Karya Ujo Noguchi". Pada artikel tersebut dijelaskan mengenai penggunaan teori Riffaterre pada lagu Shabondama karya Ujo Noguchi. Dengan menggunakan teori Riffaterre, makna sebenarnya pada lagu tersebut dapat ditemukan dan juga dipahami. Bahwa pada lirik lagu Shabondama tersebut terdapat makna yang lebih dari sekedar lagu anak tentang gelembung sabun. Melalui kajian pembacaan heuristik dan hermeneutik pada teori Riffaterre, penulis dapat mengartikan bahwa lagu tersebut dibuat sebagai gambaran mengenai anak-anak yang diibaratkan seperti gelembung sabun, transparan dan rapuh. Adapun alasan pembuatan lagu tersebut berdasarkan pembacaan hermeneutik adalah pengarang lagu memiliki anak berusia 1 minggu yang telah meninggal. Lagu Shabondama ini dibuat karena Noguchi teringat oleh nasib anaknya yang meninggal saat melihat anakanak bermain gelembung sabun. Jadi gelembung sabun yang mudah pecah tersebut diibaratkan seperti anak-anak yang masih rapuh.

Teori Riffaterre juga dikaji pada penelitian Budiana dkk (2018: 904-910) yang berjudul “Makna Syair Lagu Sakura Dalam Dua Lagu J-Pop Berjudul Sakura Karya Naotaro Moriyama dan Kentaro Kobuchi . Pada artikel tersebut juga membahas mengenai lagu Sakura, namun yang berbeda dari artikel ini adalah pembahasan yang diambil merupakan perbandingan atau mencari perbedaan dari kedua lagu yang berjudul Sakura. Dua lagu yang sama-sama berjudul Sakura ini memiliki pemaknaan lirik yang berbeda. Dengan menggunakan teori Riffaterre perbedaan makna pada lirik kedua lagu tersebut dapat ditemukan. Lagu Sakura karya Naotaro Moriyama menggambarkan kesedihan seseorang yang harus berpisah dengan sahabatnya untuk mengejar impian mereka masing-masing. Sedangkan lagu Sakura karya Kentaro Kobuchi menggambarkan seseorang yang bersedih karena tidak dapat bersatu dengan orang yang dicintainya. Perbedaan yang ada pada kedua lirik lagu tersebut dapat terlihat jelas setelah dianalisis menggunakan teori Riffaterre.Berdasarkan dari kedua kajian tersebut, pada penelitian kali ini pun penulis menggunakan teori Riffaterre sebagai kajian untuk dapat menganalisis makna dari pada lirik lagu Sakura karya Naotaro Moriyama.

\footnotetext{
${ }^{1}$ Pradopo, Rachmat Djoko.1999. Semiotika: Teori, Metode, dan Penerapannya Dalam Pemaknaan Sastra. dlm Humaniora. No.10, 1999. Yogyakarta: Universitas Gajah Mada
} 


\section{Metode Penelitian}

Metode penelitian adalah cara untuk mengumpulkan data dan mengolah data sehingga mampu menghasilkan data yang dapat memecahkan permasalahan dalam penelitian. Surakhmad (1985:131) menyatakan bahwa "metode penelitian adalah cara utama yang digunakan untuk mencapai suatu tujuan, misalnya untuk menguji serangkaian hipotesis dengan menggunakan teknik tertentu".

Dalam penelitian ini metode yang kami gunakan adalah metode deskriptif, metode kualitatif, metode studi pustaka, dan metode hermeneutika. Metode deskriptif ini dilakukan dengan membuat gambaran atau mendeskripsikan suatu objek secara akurat. Metode kualitatif dilakukan untuk menjelaskan dan menganalisis objek melalui pengumpulan datadata. Metode studi pustaka ini dilakukan dengan membaca data-data atau referensi yang berkaitan dengan objek penelitian yang kami angkat, kemudian mencatat data-data dan memberikan kode terkait data yang berhubungan. Metode hermeneutika ini dilakukan dengan menafsirkan atau menginterpretasikan sebuah kata dari teks-teks lirik lagu Sakura karya Naotaro Moriyama.

\section{Hasil dan Pembahasan}

Makna sebuah karya sastra (puisi) berdasarkan teori Riffaterre dapat diperoleh dengan melakukan 4 tahapan, yang meliputi (1) ketidaklangsungan ekspresi, (2) pembacaan heuristik dan hermeneutik, (3) matriks, model, dan varian-varian, serta (4) hipogram. ${ }^{2}$

\subsection{Pembacaan Heuristik}

Menurut Pradopo (2010:295) menjelaskan dalam pembacaan heuristik, sajak dibaca berdasarkan konvensi bahasa atau sistem bahasa sesuai dengan kedudukan bahasa sebagai sistem semiotik tingkat pertama. Pembacaan heuristik belum memberikan makna sajak atau makna sastra (significance). Oleh karena itu, karya sastra (sajak, fiksi) harus dibaca ulang (retroaktif) dengan memberikan tafsiran (Riffaterre 1978:5-6).

Berikut merupakan lirik lagu Sakura dalam pembacaan heuristik.

\section{Bait ke-1}

Pembacaan heuristik bait pertama tersebut adalah sebagai berikut.

僕らはきっと待ってる。君とまた会える日々をさくら並木の道の上で手を振り叫ぶよ。 どんなに苦しい時も君は笑っているから、挫けそうになりかけても頑張れる気がした よ。霞みゆく景色の中にあの日の唄が聴こえる。

Bokura wa kitto matteru. Kimi to mata aeru hibi wo sakura namiki no michi no ue de te wo furisakebu yo. Donna ni kurushii toki mo kimi wa waratte iru kara, kujikesou ni narikaketemo ganbareru ki ga shita yo. Kasumi yuku keshiki no naka ni ano hi no uta ga kikoeru.

Penerjemahan ke dalam bahasa Indonesia adalah sebagai berikut.

Aku pasti akan menunggu, menunggu bertemu denganmu aku akan memanggilmu sambil melambaikan tangan bertepikan pohon sakura. Waktu sesulit apapun, walaupun sepertinya tengah hancur. Aku rasa aku bisa berusaha di dalam pemandangan yang berkabut, Lagu pada hari itu mulai terdengar.

\footnotetext{
${ }^{2}$ Pradopo, Rachmat Djoko.1999. Semiotika: Teori, Metode, dan Penerapannya Dalam Pemaknaan Sastra. dlm Humaniora. No.10, 1999. Yogyakarta: Universitas Gajah Mada
} 


\section{Bait ke-2}

Pembacaan heuristik bait kedua tersebut adalah sebagai berikut.

さくらさくら今、咲き誇る。刹那に散りゆく運命と知ってさらば友よ。旅立ちの刻、変 わらない。その想いを今。

Sakura sakura ima, sakihokoru. setsuna ni chiriyuku sadame to shitte saraba tomo yo. Tabidachi no toki, kawaranai. Sono omoi wo Ima.

Penerjemahan ke dalam bahasa Indonesia adalah sebagai berikut.

Sakura, sakura kini mulai mekar. Mereka tahu takdir waktu dimana mereka akan gugur teman, kalau begitu inilah waktunya kita berjalan, meninggalkan perasaan yang tidak akan berubah, sekarang.

\section{Bait ke-3}

Pembacaan heuristik bait ketiga tersebut adalah sebagai berikut.

今なら言えるだろうか。偽りのない言葉輝ける君の未来を願う本当の言葉移りゆく街は まるで 僕らを急かすように。

Ima nara ieru darouka. itsuwari no nai kotoba, kagayakeru kimi no mirai wo negau hontou no kotoba, utsuri yuku machi wa marude bokura wo sekasu youni.

Penerjemahan ke dalam bahasa Indonesia adalah sebagai berikut.

Mungkinkah jika kini aku bisa mengucapkan Kata-kata tulus, Kata-kata tulus harapan Agar masa depanmu bersinar, Kota yang berubah-ubah seakan seperti kita yang terburu-buru.

\section{Bait ke-4}

Pembacaan heuristik bait keempat tersebut adalah sebagai berikut.

さくら さくら ただ舞い落ちる。いつか生まれ変わる。瞬間を信じ泣くな友よ。今惜別 の時 飾らないあの笑顔でさあ

Sakura, sakura tada maiochiru. Itsuka umarekawaru. toki wo shinji naku na tomo yo. ima sekibetsu no toki kannzaranai ano egao de saa.

Penerjemahan ke dalam bahasa Indonesia adalah sebagai berikut.

Sakura, sakura seperti biasa jatuh berguguran, aku percaya pada waktu dimana suatu saat akan terlahir kembali. Teman, janganlah menangis, inilah waktunya beranjak dengan tawa yang tidak dibuat-buat, ayolah.

\section{Bait ke-5}

Pembacaan heuristik bait kelima tersebut adalah sebagai berikut.

さくら さくらいざ舞い上がれ。永遠にさんざめく光を浴びて。さらば友よまたこの場 所で会おう。さくら舞い散る道の上で。 
Sakura, sakura iza maiagare. Towa ni sanzameku hikari wo abite. Saraba tomo mata kono basho de aou. Sakura maichiru michi no ue de.

\section{Penerjemahan ke dalam bahasa Indonesia adalah sebagai berikut.}

Sakura, sakura teruslah naik bermandikan sinar matahari yang berlimpah selamanya. Teman, mari kita bertemu lagi di tempat itu Tempat dimana jalan dengan sakura berguguran di atasnya.

Berdasarkan hasil pembacaan heuristik, isinya yaitu si tokoh aku akan selalu menunggumu (mu disini menunjukkan seorang sahabat), menunggu untuk bertemu lagi. aku akan memanggilmu dan melambaikan tangan di jalan bertepikan pohon sakura. Tak peduli sesulit apapun itu, kamu selalu akan bisa tersenyum walaupun sepertinya tengah hancur, aku rasa aku bisa berusaha melakukan yang terbaik. Meskipun, pemandangan berkabut hiingga lagu itu mulai terdengar. Sakura kini mulai bermekaran, mereka tahu takdir waktu dimana mereka akan gugur. Sahabat, inilah waktunya kita berjalan dan meninggalkan perasaan yang tidak akan berubah bahkan sampai sekarang.Bisakah kini aku bisa mengucapkan kata-kata tulus. Kata- kata tulus yang penuh harapan. Agar masa depanmu bersinar. Kota yang berpindah seakan seperti kita yang terburu-buru. Seperti biasa bunga sakura yang bermekaran akan jatuh berguguran. Aku percaya pada waktu, dimana suatu saat akan terlahir kembali.

Sahabat, janganlah menangis, inilah waktunya untuk kita beranjak dengan tawa yang tidak dibuat-buat, ayolah. Sakura, teruslah naik, Bermandikan sinar yang berlimpah selamanya. Sahabat, kalau begitu mari kita bertemu lagi di tempat itu, tempat di mana jalan dengan sakura berguguran, tempat dimana jalan dengan sakura berguguran di atasnya.

\subsection{Pembacaan Hermeneutik}

Pembacaan hermeneutik, menurut Pradopo (2010:297), adalah pembacaan ulang dari awal sampai akhir dengan penafsiran atau pembacaan hermeneutik. Pembacaan ini, adalah pemberian makna berdasarkan konvensi sastra. Puisi menyatakan suatu gagasan secara tidak langsung, dengan kiasan (metafora), ambiguitas, kontradiksi, dan pengorganisasian ruang teks.

Dalam lirik lagu tersebut, ditemukan penggunaan ekspresi yang tidak langsung. Untuk lebih jelasnya, sebagai berikut :

\section{a. Majas simile}

Majas simile adalah majas perbandingan atau perumpamaan yang menyamakan satu hal dengan menggunakan kata-kata pembanding (bagaikan, bak, laksana, seperti dII). Dalam bahasa Jepang penggunaan majas simile ditandai dengan penggunaan you ni. Penggunaan majas simile pada lirik lagu, dapat dilihat pada bait 4 larik 3.

Utsuriyuku machi wa marude, bokura wo sekasu you ni

(Kota yang berubah seakan memaksa kita tergesa-gesa)

Pada larik tersebut, "kota yang berubah" dan "tergesa-gesa" mengandung arti perubahan yang terjadi pada kota seperti menggambarkan waktu yang terus berjalan dan keadaan yang silih berganti. Waktu yang terus berjalan dan keadaan yang silih berganti membuat kita seakan-akan memaksa atau mengharuskan kita untuk tetap bergerak mengejar impian kita. Pada bagian ini, penyanyi memberikan pesan yang tidak langsung yaitu kita harus bersiap diri ataupun mempersiapkan segala sesuatu untuk menghadapi keadaan yang berubah-ubah setiap detiknya. 


\section{b. Majas metafora}

Sakura sakura iza maiagare, towa ni sanzameku hikari wo abite

(Sakura sakura terbang tinggi, bermandikan cahaya yang berlimpah selamanya)

Pada larik lagu tersebut terdapat majas metafora, dimana pada kalimat "Sakura sakura iza maiagare" bunga sakura yang terbang tinggi diibaratkan sebagai impian yang harus di gapai setinggi mungkin. Sedangkan pada kalimat "towa ni sanzameku hikari wo abite" mengibaratkan cahaya yang berlimpah selamanya sebagai harapan dan semangat yang harus kita miliki untuk menggapai impian yang tinggi tersebut. Pada Sakura bagian ini, sakura disimbolkan sebagai sahabat penyanyi. Penyanyi berharap agar sahabatnya dapat meraih impian setinggi langit dan semangat yang tinggi. Pada bagian ini menekankan makna impian.

Selain menemukan ketidakberlangsungan ekspresi, juga ditemukan kontradiksi pada bait 1 larik ke 4, yaitu.

\section{Kujikesou ni nari kakete mo, ganbareru ki ga shita yo}

(Walaupun sepertinya tengah hancur, aku rasa aku bisa berusaha melakukan yang terbaik)

Kontradiksi pada larik lagu ini dapat diketahui melalui penggambaran "aku" yang merasa bisa tetap berusaha meskipun hatinya sedang hancur. Biasanya jika berada pada situasi yang seperti itu hal yang dilakukan/dirasakan adalah putus asa, bersedih, dan lain sebagainya. Namun, pada larik tersebut digambarkan bahwa ia tetap yakin dirinya mampu berusaha di situasi yang membuat hati atau perasaannya hancur.Larik ini berkaitan dengan larik sebelumnya yang mengatakan "Waktu sesulit apa pun, karena kamu akan selalu bisa tersenyum". Kujikesou adalah konotasi negatif (kecewa, kehancuran ), ganbareru berasal dari bentuk ganbaru yang memiliki konotasi positif yaitu bertahan atau semangat yang tinggi.

Naotaro Moriyama, mendeskripsikan bahwa tokoh si aku akan selalu menunggu seorang sahabatnya. Sakura yang bermekaran dapat dijadikan sebagai penanda bahwa waktunya untuk berpisah. Berpisah untuk meraih impian. Dan sakura yang berguguran dapat dijadikan sebagai tanda pertemuan yang diyakini oleh penyanyi. Pada bagian ini, memiliki makna yaitu harapan untuk bertemu kembali

\section{Kesimpulan}

Dalam pemaknaan puisi atau lirik lagu Sakura, penulis telah menjabarkan tentang pemaknaan lirik Sakura berdasarkan teori semiotika puisi Riffaterre. Lagu Sakura, adalah lagu yang menceritakan tentang perpisahan seorang sahabat untuk meraih impiannya. Untuk menemukan makna yang sebenarnya, kita dapat melihat dari hasil kajian pembacaan heuristik dan pembacaan hermeneutik. Pada lagu ini, memiliki makna yang sangat mendalam yaitu perpisahan dengan sahabat karena impian, impian, dan harapan penyanyi untuk bertemu kembali dengan sahabatnya.

\section{Daftar Pustaka}

Dewi, N.M.P, Damayanti, S., \& Budiana, I.M. Semiotika dalam Lagu Che. r.ry dan Summer Song Karya Yui Yoshioka. Humanis 22.4 (2018): 904-910. Diakses pada: 25 April 2021

Huri, R.M., Yenni, H., \& Ismail, M. Analisis Semiotika Riffaterre dalam Puisi Dongeng Marsinah Karya Sapardi Djoko Damono. Jurnal Bahasa dan Sastra 5.1 (2017): 52-66. Diakses pada : 25 April 2021 
Noviana, F., \& Saifudin, A. Pemaknaan Lirik Lagu Shabondama Karya Ujo Noguchi Berdasarkan Analisis Semiotika Michael Riffaterre. Japanese Research on Linguistics, Literature, and Culture 2.2 (2020): 143-160. Diakses pada : 25 April 2021

Muchti, A. 2017. Kajian Heuristik dan Hermeneutik terhadap Kumpulan Puisi Deru Campur Debu Karya Chairil Anwar."

Patria, R., Abdurahman, A., \& Nasution, B. Interpretasi Makna Lirik Lagu-lagu Grup Musik ERK Dalam Album ERK: Kajian Semiotika. Jurnal Bahasa dan Sastra 1.2 (2013): 6982. Diakses pada : 25 April 2021

Pradopo,R.D. 2010. Pengkajian Puisi. Yogyakarta.Gadjah Mada University Press.

Pradopo, R.D. 1999. Semiotika: Teori, Metode, dan Penerapannya Dalam Pemaknaan Sastra. dlm Humaniora. No.10, 1999. Yogyakarta: Universitas Gajah Mada.

Pradopo, R.D.1987. Pengkajian Puisi. Yogyakarta: Gajah Mada University Press.

Praharsacita, C.A., Damayanti, S., Budiana, I.M. "Makna Syair Lagu Sakura Dalam Dua Lagu J-Pop Berjudul Sakura Karya Naotaro Moriyama Dan Kentaro Kobuchi." Jurnal Humanis, Fakultas IImu Budaya Unud 1.7 (2016): 33-41. Diakses pada : 25 April 2021

Ratih, R. 2017. Teori dan Aplikasi Semiotik Michael Riffaterre. Yogyakarta: Pustaka Pelajar. 